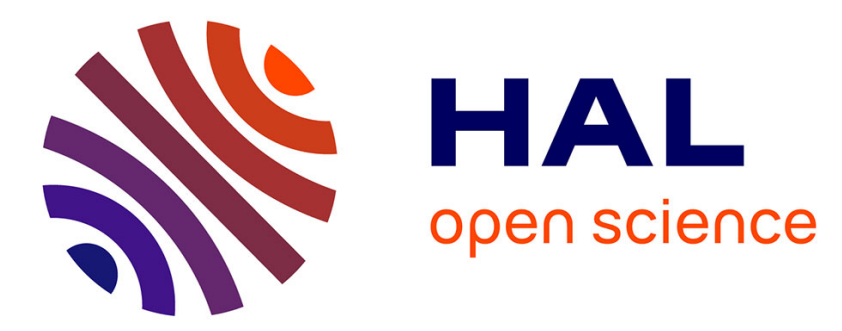

\title{
Plasticity of reproductive allocation of a woody species (Ulex europaeus) in response to variation in resource availability
}

Florian Delerue, Maya Gonzalez, Anne Atlan, Sylvain Pellerin, Laurent Augusto

\section{To cite this version:}

Florian Delerue, Maya Gonzalez, Anne Atlan, Sylvain Pellerin, Laurent Augusto. Plasticity of reproductive allocation of a woody species (Ulex europaeus) in response to variation in resource availability. Annals of Forest Science, 2013, 70 (3), pp.219-228. 10.1007/s13595-012-0260-x . hal-00834280

\section{HAL Id: hal-00834280 \\ https://hal.science/hal-00834280}

Submitted on 29 May 2020

HAL is a multi-disciplinary open access archive for the deposit and dissemination of scientific research documents, whether they are published or not. The documents may come from teaching and research institutions in France or abroad, or from public or private research centers.
L'archive ouverte pluridisciplinaire HAL, est destinée au dépôt et à la diffusion de documents scientifiques de niveau recherche, publiés ou non, émanant des établissements d'enseignement et de recherche français ou étrangers, des laboratoires publics ou privés.

$$
\text { Copyright }
$$




\title{
Plasticity of reproductive allocation of a woody species (Ulex europaeus) in response to variation in resource availability
}

\author{
Florian Delerue • Maya Gonzalez • Anne Atlan • \\ Sylvain Pellerin • Laurent Augusto
}

Received: 8 October 2012 / Accepted: 27 December 2012 /Published online: 17 January 2013

(C) INRA and Springer-Verlag France 2013

\begin{abstract}
- Context While many woody perennials grow and reproduce in varying environments, their ability to modify their reproductive allocation under varying resource availability is unclear.

- Aims This study aimed to demonstrate the occurrence of plasticity of reproductive allocation in a pioneer woody species (Ulex europaeus).

- Methods We studied seed production in 144 plants under different irradiance and population densities. We measured their basal area, their whole shoot biomass and photosynthetic biomass, and their reproductive output (number of fruits per individual and number of seeds per fruit).

- Results We found that newly produced photosynthetic biomass was influenced by environmental variation, which in turn determined plants' reproductive output. In addition, in low light conditions investment in reproduction was more
\end{abstract}

Handling Editor: Erwin Dreyer

Electronic supplementary material The online version of this article (doi:10.1007/s13595-012-0260-x) contains supplementary material, which is available to authorized users.

Contribution of the co-authors F.D, M.G and L.A designed the experiment. F.D ran the data analysis. All the authors participated in interpreting the results and writing the paper.

F. Delerue $\cdot$ M. Gonzalez $(\bowtie) \cdot S$. Pellerin $\cdot$ L. Augusto UMR 1220, TCEM, Institut National de la Recherche Agronomique, 33140 Villenave d'Ornon, France e-mail: maya.gonzalez@agro-bordeaux.fr

F. Delerue $\cdot$ M. Gonzalez

UMR 1220 TCEM, Université de Bordeaux,

33883 Gradignan, France

A. Atlan

UMR 6553 ECOBIO, Centre National de la Recherche

Scientifique, Université de Rennes 1, 35042 Rennes, France reduced than investment in growth indicating plasticity of reproductive allocation.

- Conclusion These results provide the first evidence for plasticity of reproductive allocation of a woody plant. It may lead to the ability of this pioneer species to survive and to continue to reproduce even at low rates in non-optimal shady habitats and to maintain a non-empty seed bank in forest systems with long unfavourable periods between two disturbances.

Keywords Woody perennials · Reproductive ecology · Sizedependent reproductive output $\cdot$ Light $\cdot$ Density $\cdot$ Pioneer woody shrub · Forest succession $\cdot$ Successional niche hypothesis $\cdot R$ - $V$ relationship $\cdot$ Allometric relationship . Shade avoidance

\section{Introduction}

Many polycarpic woody plants go through successive growing and reproductive episodes in varying environments. For example, pioneer woody shrubs establish early in the forest succession and some of them persist until competition increases and tree canopy closure strongly decreases light availability (e.g. Abe et al. 2008).

When resource availability is limited, allocation to reproduction or growth may interfere, and high investment in reproduction may be hazardous (Obeso 2002). Thus, to maximise offspring production without jeopardising further growth and survival, it could be advantageous for a woody perennial to adjust the amount of resource allocated to reproduction to the availability of resource. Reproducing within a large gradient of resource availability, some pioneer shrubs species could particularly benefit from plasticity of their reproductive allocation. 
Reproduction consumes carbohydrates and nutrients provided by vegetative tissues. As a consequence, plants show species-specific relationships between reproductive output $(R)$ and vegetative $(V)$ biomass. These relationships (hereafter referenced to as ' $R$ - $V$ relationships') can be linear, allometric (i.e. $R=k V^{\alpha}$ ) or involve more complex shapes (Klinkhamer et al. 1992). Therefore, when individuals of the same species are exposed to different resource availability, they grow to different sizes and their reproductive output is mainly determined by their position on the $R-V$ relationship. 'True' plasticity of reproductive allocation implies a change in the $R-V$ relationship and differs from 'apparent' plasticity that just involves a change in the growth rate (i.e. 'apparent plasticity') (Weiner 2004).

In woody plants, the main size parameter used to fit these $R-V$ relationships was tree diameter (e.g. Dodd and Silvertown 2000). In resource-rich environments (e.g. higher irradiance (Jennings and Baima 2005), lesser density of neighbours (Debain et al. 2003)), trees with the same initial diameter show higher reproductive output. But any conclusion on the ability of woody plants to modify their reproductive allocation is premature. With the same initial diameter, if trees with a higher reproductive output also had a higher growth rate, the proportion of resource allocated to reproduction would simply remain unchanged. Therefore, to address the question of reproductive allocation of woody plants, the actual reproductive output and the actual or recent growth rate in relation with the actual availability of resource should be considered explicitly in the $R-V$ relationships (Weiner et al. 2009a).

Niklas and Enquist (2003) showed that leaf biomass is a more efficient predictor of reproductive output than stem or root biomass. Indeed, photosynthetic biomass (PB) is well correlated with the carbohydrates available for all plant functions including reproduction. Consequently, we assumed that using the relationship between PB and reproductive output is an appropriate approach to track modifications in the reproductive allocation of woody plants (see Fig. 1).

However, resource allocation is expected to evolve with plant development (McConnaughay and Coleman 1999). For example, as woody plants grow, their proportion of $\mathrm{PB}$ in the whole shoot biomass (hereafter referred to as the $P B$ / shoot ratio) decreases. The proportion of non-photosynthetic support tissue correspondingly increases. The cost to maintain support tissue could increase too and decrease reproductive allocation (Peters et al. 1988). Thus, to demonstrate occurrence of 'true' plasticity of reproductive allocation, changes in $R-V$ relationships using PB must be independent to changes due to plant development (Online resource 1). Therefore, the influence of other variables related to ontogeny (e.g. the PB/shoot ratio, the number of wood rings) on the $R-V$ relationships have to be taken into account.
In the present study, we took advantage of the spontaneous presence of a pioneer shrub of moderate size (Ulex europaeus L), in a wide range of irradiance conditions and intra-specific competition in the understory of a planted forest, to investigate if its reproductive allocation was plastic along the gradients of resource and competition studied. We fitted different $R-V$ relationships, using $\mathrm{BA}$ or $\mathrm{PB}$ as main proxies for vegetative tissues, and we examined the influence of environmental variations on these $R-V$ relationships to disentangle apparent and true plasticity of reproductive allocation (see Fig. 1).

\section{Materials and methods}

\subsection{Model species and region of the study}

U. europaeus L. (common gorse, hereafter referred to as gorse) is an evergreen leguminous shrub native to the Atlantic European coast. The study was conducted in 2010 and 2011 in the 'Landes de Gascogne' forest of planted maritime pine (Pinus pinaster Ait) in southwest France. This forest is characterised by poor acidic sandy soils, forming an oligotrophic environment. In this forest, gorse shrubs often grow and reproduce in a high intra-specific and relatively low inter-specific understory since: (1) gorse is taller than the other understory species, and (2) as a pioneer and light-demanding species (Lee et al. 1986), it commonly forms dense mono-specific thickets in very young pine stands with full light exposure. However gorse can maintain itself in old forest stands where less light reaches the understory because of interception by the tree stratum. Thus, it can also grow and reproduce under different light conditions.

After two growing seasons, gorse reproduces once a year. Its onset and duration of reproduction is variable. This polymorphism is under genetic control (Atlan et al. 2010) and is expressed through: (1) plants with a long flowering period from winter to spring or (2) plants with a short and abundant flowering period in spring. In this study, we focused on the plants of the second group which are by far the most frequent in our study area. Their flowering involves a cycle of two successive years (Online Resource 2). In year 1, new photosynthetic shoots (i.e. green stems with prickly leaves) are produced at the end of the previous year's shoots, the latter being transformed into non-photosynthetic supporting tissues. Thus, the proportion of non-photosynthetic support tissue increases as the plant grows (Puentes and Basanta 2002). Flowering occurs in early spring after winter dormancy in year 2. Pods mature and seeds are filled from May to the beginning of July before their dispersal by explosive dehiscence of pods. New shoots grow at the end of the reproductive season. The species is self-compatible but visit of flowers by 


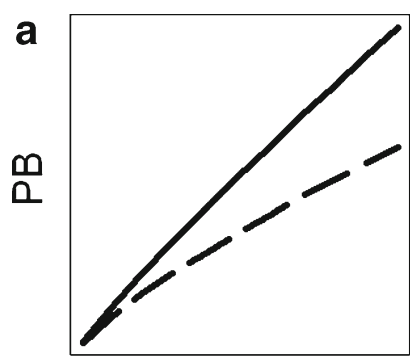

BA

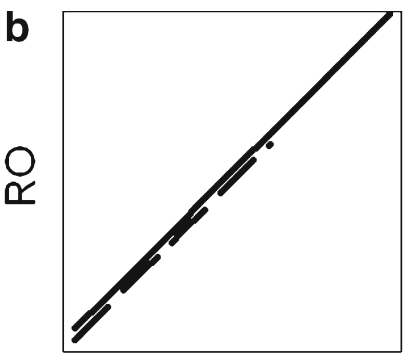

PB

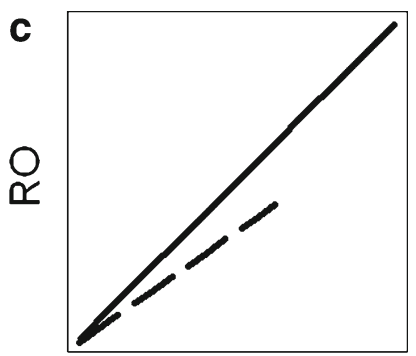

PB
Fig. $1 R-V$ relationships using $\mathrm{PB}$ as an appropriate tool to distinguish between 'apparent' and 'true' plasticity of the reproductive allocation for woody plants growing in low (broken lines) and rich (solid lines) resource availability. $B A$ basal area, $P B$ photosynthetic biomass, $R O$ reproductive output. The production of $\mathrm{PB}$ increases with plant size (BA) but decrease in case of low resource availability (a). In a first scenario, allocation to reproduction is equal in both poor and rich

bees or bumblebees is needed for fecundation. In its native area, gorse flower visitation is not limited (Bowman et al. 2008) because of the abundance of pollinators (Louveaux et al. 1966).

\subsection{Experimental design and measurement of variables}

\subsubsection{Selection of sites and individuals}

We took advantage of light interception by the pine overstory to build our first experimental gradient of light availability. In addition, we studied plants along a second gradient of density and intra-specific competition for resource. The two gradients studied were not crossed in our experimental design.

We repeated the following steps during the two successive years. First, we selected three sites with different light availability after a coarse estimation of light interception by the pine canopy (based on pine leaf area index calculated using tree dimensions (Porte et al. 2000)). Another site was selected in full light conditions. Avoiding winter flowering individuals, we selected 12 isolated gorse bushes per site (i.e. with no or few conspecific neighbours within a radius of $2.5 \mathrm{~m}$ ). We chose individual plants representing a wide range of sizes to study reproductive allocation of the species over its whole size range (Online Resource 3). However, we avoided very small bushes (height $<1.0 \mathrm{~m}$ ). At the site with full light conditions, we identified each year two plots with moderate and high densities of gorse bushes in addition to the 12 isolated shrubs. In the densest plot, we opened a narrow access path to the centre of the plot where we selected 12 individuals of different sizes.

In practice, our sampling was split between (Online Resource 3): (1) the light gradient composed of eight plots (six in the understorey and two outside the forest). Twelve gorse bushes were monitored in $400 \mathrm{~m}^{2}$ plots, except in the environments. Thus the $R-V$ relationships between $\mathrm{PB}$ and $\mathrm{RO}$ remain unchanged (b). Because of differences in the production of PB (a), the $R-V$ relationships using BA will differ in low and rich resource availability (i.e. apparent plasticity of reproductive allocation). In a second scenario, allocation to reproduction is plastic (lower in poor environments). Thus the $R-V$ relationships between PB and RO show two distinct lines (c) as indicator of this true plasticity.

shadiest plot where we found only eight individuals, i.e. a total of 92 individuals composed the light gradient; (2) the density gradient composed of 72 gorse bushes all located under full light conditions (i.e. 3 levels of density $\times 2$ years $\times$ 12 plants). The 'low density' level referred to isolated gorse bushes (see above) scattered throughout the site. The 'medium density' and 'high density' levels were studied in two $64 \mathrm{~m}^{2}$ plots $(8 \times 8 \mathrm{~m})$. On the whole, a total of 140 individuals were sampled in the study (144-4 exclusions because of obvious operator mistakes).

\subsubsection{Heterogeneity of sites and years sampled}

A few plots showed differences in soil nutrient contents (determined from three soil samples) or in the understory composition (Online Resource 3, plots Li-4, Li-5 and De-4). However, these differences were not organised in the same way as the light or density gradients. 'Non-gorse' understory biomass (in gram per square metre) decreased under low light availability and in dense gorse thickets (Online resource 3). Rainfall and temperatures were similar in the two seasons of $\mathrm{PB}$ production, whereas the spring was drier and hotter in 2011 (Online resource 3).

\subsubsection{Measurement of reproductive variables}

Each year, we measured the two main components of the reproductive output of shrubs: the number of fruits produced and the number of seeds per fruit. We visited all sites every 2 weeks from complete maturation of the first pods (end of May) until the end the reproductive period (beginning of July). We counted all the ripe (brown to black) pods on each shrub sampled and harvested them before the pod opened. To estimate the number of seeds per pod, we randomly opened 20 pods per harvesting date and per individual if available (otherwise we opened all the pods we had 
collected), i.e. a total of 4,169 pods opened. The number of seeds per pod used in this paper refers to seed production before predation by the gorse seed weevil (Exapion ulicis) and the gorse pod moth (Cydia succedena). As each weevil larvae generally feeds on one seed (Barat et al. 2007), we estimated the original number of seeds per pod by adding the number of larvae and the number of undamaged seeds. After predation by the pod moth larvae, we were often not able to estimate the original number of seeds.

\subsubsection{Measurement of size variables}

We harvested the whole shoot of sampled individuals soon after reproduction ended. We measured their stem basal area (BA) at $10 \mathrm{~cm}$ from the soil surface with a calliper and counted their total number of wood rings as a proxy of their age. Their BA during dormancy the preceding winter was obtained by subtracting the width of their last ring from their stem diameter at harvesting time. Then, their shoot biomass was split between PB and the rest of supporting biomass, dried and weighed.

\subsubsection{Determination of light and density indexes}

Light index Selection of sites was based on a first coarse estimate of light interception by the canopy (see above). A light index (LI) was determined using a more accurate method after the ending of reproduction. Following Gendron et al. (1998), under a completely overcast sky, one-off comparison of the photosynthetically active radiation (PAR) received simultaneously by the understory and at a nearby canopy-free area provides a reliable estimation of the seasonal mean percentage of PAR received by the understory. We used this 'overcast' method both years in summer, within the same 2 weeks period. Two operators simultaneously measured the signal of two PAR sensors during two series of 30-s measurements under adequate cloud cover. One sensor was placed at the apex of the sampled shrub; the other one was placed at the same height in a close open area. Finally, the ratio of the two signals (understory/open area) was expressed in percent to create the LI (Online Resource 3).

Density index By the end of summer, we had cut, measured (stem basal area) and mapped all gorse plants growing in the density plots. Conspecific neighbours at all sites located within a $2.5-\mathrm{m}$ radius of targeted individuals were also measured and mapped (Online Resource 3), i.e. a total of 3,089 gorse plants mapped in the whole study. The width of the last wood ring was measured in a subsample in each plot. Then, we used the relationship between the BA measured and the width of the last wood ring in each plot to estimate the BA of all competitors in the preceding winter. Finally we calculated a density index (DI) using the distance between competitors and target individuals and the BAs in the preceding winter.

We selected Hegyi's density index (Hegyi 1974, stated in Eq. 1, Online Resource 4) because it takes into account (1) population spatial heterogeneity (it is distance dependent) and (2) size-asymmetric competition (it compares the size of the target individual with that of the competitor). Many competitors concentrated on the same side of one individual provide preferential access to resource on the opposite side. To account for the spatial distribution of competitors, we modified Hegyi's index according to Newton and Jolliffe (1998), given the position of the centre of mass of the competitors (Online Resource 4). Other spatialised density indexes were also built and tested during analyses but did not perform better (Online Resource 4)

\subsection{Data analysis}

First, we verified the influence of the environment on the production of $\mathrm{PB}$ and on ontogenic variables (e.g. the $\mathrm{PB} /$ shoot ratio). Then, $R-V$ relationships were built for (1) the number of pods produced by each plant and (2) the total number of seeds produced by each shrub (as the number of pods multiplied by the mean number of seeds per pod). All $R-V$ relationships were fitted on a log-log scale to normalise the variables. Thus, they correspond to standard allometric $R$ - $V$ relationships (i.e. $R=k$ $V^{\alpha} \Leftrightarrow$ or $\ln R=\alpha \ln V+\ln k, \alpha$ being the scaling exponent). To test for modifications in the $R-V$ relationships under different levels of LI or DI (i.e. changes in the scaling exponent $(\alpha)$ ), we split our sample into three LI and DI classes of equal size, respecting the distribution of the tertiles (LI ranging from 15 to $42 \%$ - shady class; 43 to $88 \%$ - medium light class and 89 to $100 \%$ - full light class). Equivalently, DI classes were named sparse, medium density and dense.

For relationships predicting the production of pods, we used both $\mathrm{BA}$ and $\mathrm{PB}$ as the main explanatory variables.

- $R-V$ relationships using BA were as follows (Eq. 1):

$$
\ln R_{i}=a_{j} \ln B A_{i}+\ln k_{j}+\varepsilon_{\mathrm{i}}
$$

where $\alpha_{j}$ is the scaling exponent (and $\ln k_{j}$ the intercept) for the $j$ th LI or DI class and $\varepsilon_{i}$ is the residual of the allometric model for the $i$ th individual. Using Eq. 1, we expected strongly significant differences between the scaling exponent of the LI and DI classes (i.e. strong apparent plasticity of the reproductive output). Indeed, this first kind of $R-V$ relationships does not take into account the influence of the environment on the production of $\mathrm{PB}$, and thus on the availability of carbohydrates.

- $R-V$ relationships using $\mathrm{PB}$, with additional variables related to ontogeny (the $\mathrm{PB} /$ shoot ratio or the number 
of wood rings), were also fitted (Eq. 2; example with $\mathrm{PB} /$ shoot ratio):

$$
\ln R_{i}=\alpha_{j} \ln \mathrm{P} B_{i}+b \ln (\mathrm{PB} / \mathrm{shoot})_{i}+\ln k_{j}+\varepsilon_{i}
$$

Equation 2 takes into account (1) the modification of PB production with environment variation and (2) the possible modification of the $R-V$ relationship due to ontogeny. Thus, we expected much less significant differences between the scaling exponents of the different LI and DI classes than in Eq. 1, and significant differences between the $\alpha_{j}$ indicate true plasticity of reproductive allocation.

For relationships predicting the production of seeds, we investigated if the LI and DI class, or any other explanatory variable, had an effect on the mean number of seeds per pod. Plants for which we were not able to count the number of seeds per fruit in a minimum of 15 pods were excluded from this analysis. Finally, we reanalysed the $R-V$ relationships for the total number of seeds produced by each individual shrub.

\subsection{Statistical analyses}

Light and density datasets were analysed independently. In the density plots, some targeted individuals were competitors of other sampled individuals, causing nonindependence between observations. Therefore, we performed 1,000 random permutations of the DI of individuals within the density plots to estimate the significance of the models using DI.

We performed all data analyses using $\mathrm{R}$ software ( $\mathrm{R}$ Development Core Team 2010). We used the 'nlme' package to fit non-linear mixed models and the 'Ime4' package for general linear mixed models. We used random effects when we suspected uncontrolled effects (e.g. site effect) or to control for dependence between observations (the same shrub used for several measurements of the number of seeds per pod). ANCOVA analysis was used to test differences of the scaling exponent $\alpha$ in Eqs. 1 and 2 between different LI or DI classes. The effect of the year of the study was tested similarly. The non-significant intercepts in Eqs 1 and $2(\ln k)$ were removed from analyses. Reduced major axis regression (RMA) is generally more suitable than ordinary least square regression (OLS) to fit allometric relationship in a $\log -\log$ scale. However, RMA regressions were not used in our study because available procedures in R software (1) do not enable to fit random effects for the different sites samples, (2) are not designed for multiple regressions (like in Eq. 2) and (3) OLS and RMA regressions gave consistent results when performing the latter approach was possible (data not shown).
We modelled the number of seeds per pod with a generalised linear mixed model with Poisson distribution and log link function.

Nested mixed models with different fixed or random effects were fitted respectively with maximum likelihood and restricted estimation of maximum likelihood. They were compared with likelihood ratio tests, correcting the $P$ values following Zuur et al. (2009). Modelling efficiency (ME, the ratio of the sum of squares of the model residuals to that of the null model using the sample mean as a predictor) was used to compare the models for continuous response variables.

\section{Results}

3.1 Effect of the environment on the production of PB and on the $\mathrm{PB} /$ shoot ratio

We found significant allometric relationships between PB and individual BA (Online Resource 5). Light positively influenced this relationship. The random permutation test of shrubs DI within density plots gave a marginal result $(P<$ 0.1 , Online Resource 5). On the whole, these relationships are consistent with our Fig. 1a. Correspondingly, the PB/ shoot ratio decreased with increasing individual $\mathrm{BA}$, decreasing irradiance and increasing conspecific densities (Online Resource 5) consistently with our figure in Online Resource 1.

\subsection{Comparison of the $R-V$ relationships using $\mathrm{BA}$ and $\mathrm{PB}$} (Eqs. 1 and 2)

In Eq. 2, the explanatory variables related to ontogeny were not significant (e.g. $P=0.24$ and $P=0.47$ in the light and density samples respectively for the $\mathrm{PB} /$ shoot ratio) and this equation was simplified to: $\ln R_{i}=a_{j} \ln P B_{i}+\ln k_{j}+\varepsilon_{\mathrm{i}}$.

In the light sample, the ME of both $R-V$ relationships using either $\mathrm{BA}$ or $\mathrm{PB}$ were improved when LI class was taken into account, but the relationship using $\mathrm{PB}$ was much less influenced (Fig. 2a, b). ANCOVA revealed highly significant differences between the slopes of the different light classes using BA (Fig. 2a), while these differences were less pronounced using PB (Fig. 2b). In the density sample, adding DI class to the relationships did not improve model predictions (Fig. 2c, d). On the whole, using PB rather than BA led to better ME. Moreover, using BA, we found a significant difference of slopes between the 2 years of the study in the density sample $(P=0.002$, Fig. 2c), while with $\mathrm{PB}$, the difference disappeared (Fig. 2d). 

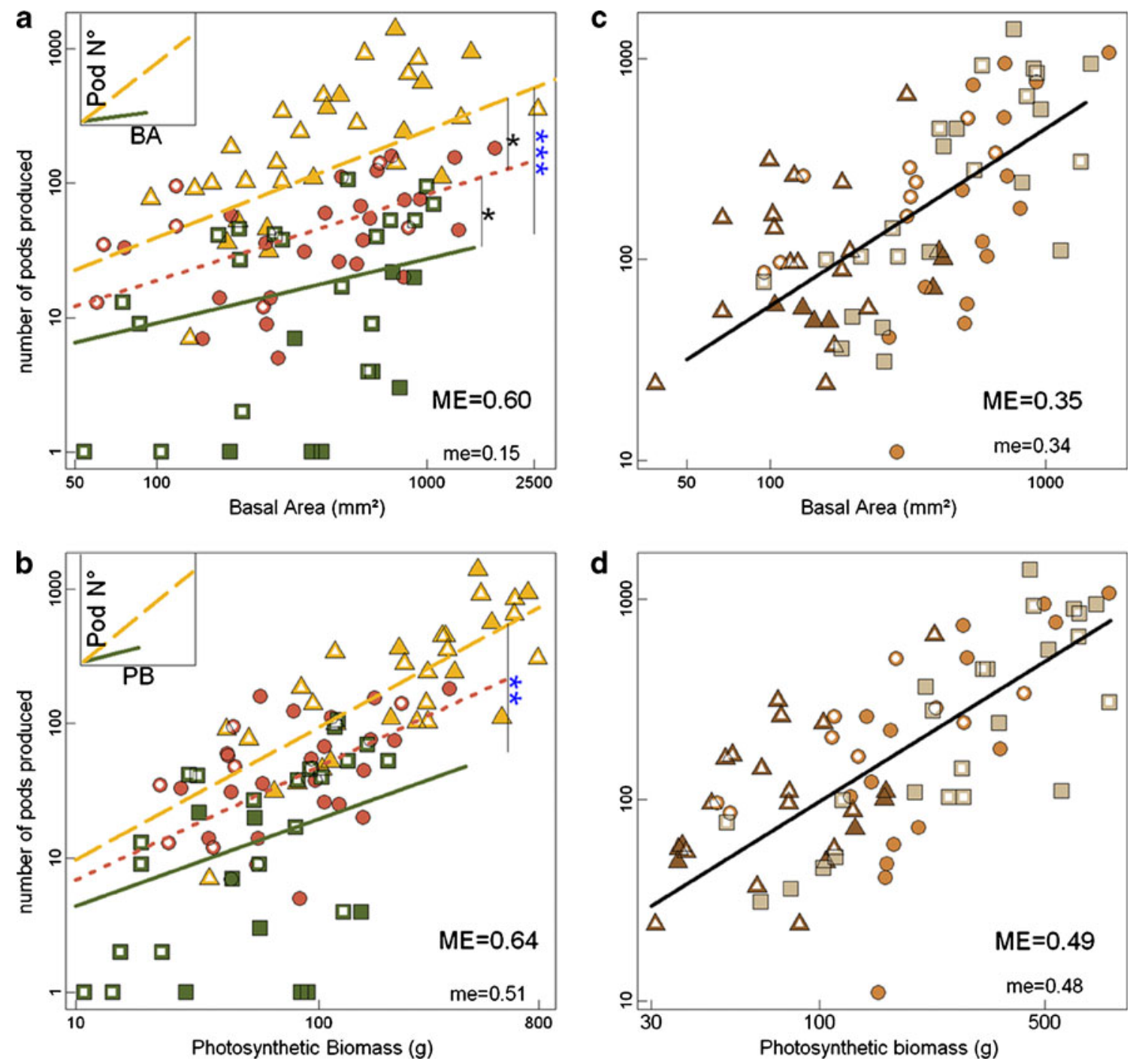

Fig. 2 Different $R-V$ relationships (using basal area (a, c) or photosynthetic biomass $(\mathbf{b}, \mathbf{d})$ ) to explain pod production under different levels of light (a, b) and of density $(\mathbf{c}, \mathbf{d})$. We added one to the number of pods produced by each shrub before log transformation because some individuals did not produce any pod. In the top left corner $(\mathbf{a}, \mathbf{b})$, the slope of the relationships on the natural scale are given for the shady and full light class. Stars indicate differences in the slope parameters $(* P<0.05 ; * * P<0.01 ; * * * P<0.001)$. Black stars show differences between adjacent slopes, blue stars between the most distant slopes. In the bottom right corner, the ME of the fitted relationships taking environmental variables into account (belonging to LI or DI classes) or not are given respectively in capital and lowercase letters. Individuals sampled in 2010 and 2011 are indicated

3.3 Changes in the $R-V$ relationships using PB (Eq. 2) due to environmental variation

In the light sample, the slopes of the $R-V$ relationships between $\mathrm{PB}$ and pod production differed significantly between the shady and full light classes (Fig. 2b). As a continuous variable, LI also significantly influenced the slope of the $R-V$ relationship (Online Resource 5). respectively by empty and filled symbols. a, b Relationships for each LI class are represented by different types of line. c, $\mathbf{d}$ In the density sample, we present the overall relationship as a black solid line (no differences of slopes between classes). a, b Green filled squares, green empty squares and solid line: the shady class $(\mathrm{N}=28(30-2$ operator mistakes)), orange filled circles, orange empty circles and dotted line: the medium light class $(N=30$ (31-1 operator mistake)), yellow filled triangles, yellow empty triangles and dashed line: the full light class $(N$ =31). c, d Light brown filled squares, light brown empty squares: the sparse density class $(N=24)$, brown filled circles, brown empty circles: the medium density class $(N=24)$, dark brown filled triangles, dark brown empty triangles: the dense class $(N=23(24-1$ operator mistake))

Moreover, the number of seeds per pod increased with LI (Online Resource 5), with more seeds per pod in the full light class (Fig. 3a). However, using pod or total seed production led to similar results (Fig. 2b, Fig. 3b).

In the density sample, we did not observe any difference in $R-V$ relationships between DI classes for pod production (Fig. 2d). When we analysed the number of 

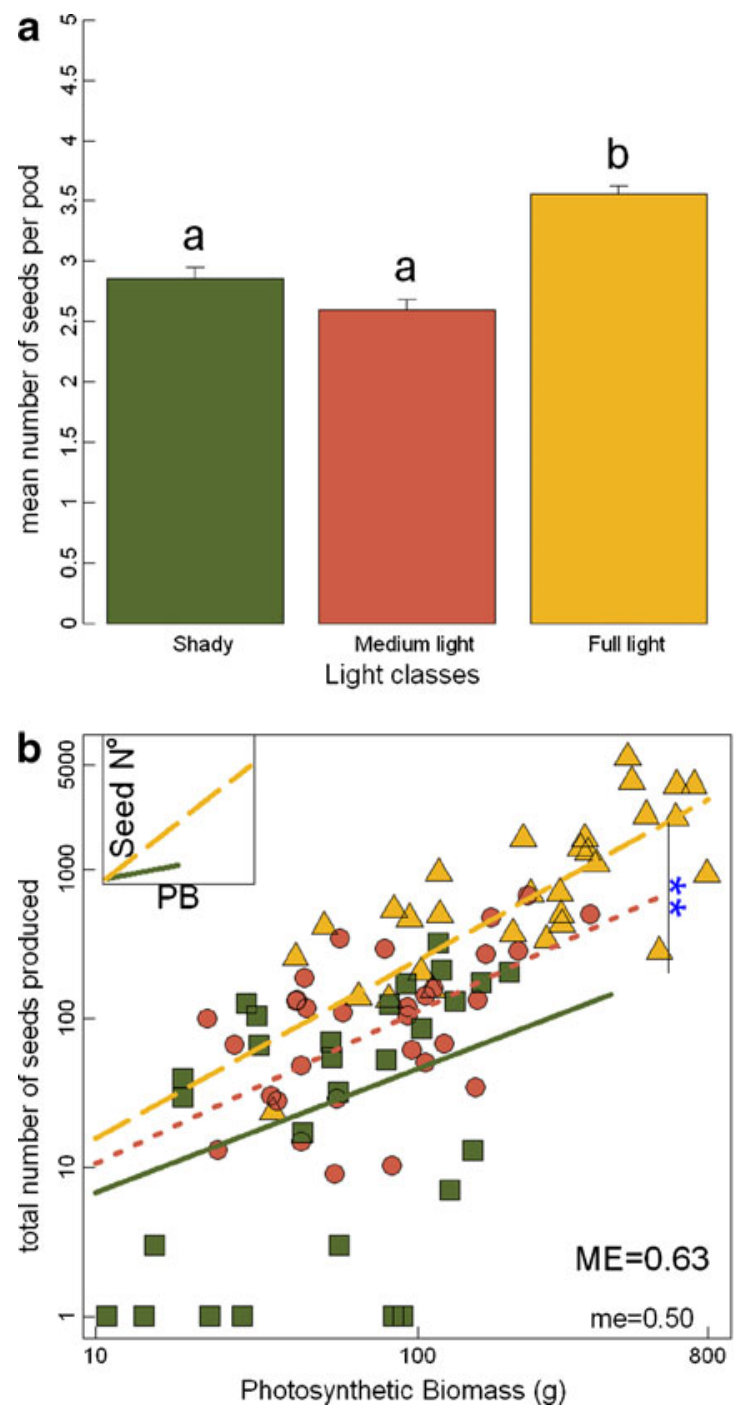

Fig. 3 Number of seeds per fruit $(\mathbf{a}, \mathbf{c})$ and $R-V$ relationships between total seed production per individual and photosynthetic biomass $(\mathbf{b}, \mathbf{d})$ under different levels of light $(\mathbf{a}, \mathbf{b})$ and of density (c, d). a, c Lowercase letters indicate a significant difference in the number of seeds per pod between LI classes and density plots. Vertical lines are standard errors. Three hundred, 359 and 847 pods were opened on 11,15 and 27 individuals in the shady, medium light and full light classes, respectively. Six hundred thirty-six, 675 and 641 pods were opened on 21, 23 and 21 individuals in the low density plots, medium density plots and high density plots, respectively. $\mathbf{b}, \mathbf{d}$ We added one to the number of seeds produced by each shrub before log transformation because some individuals did not

seeds per pod, random permutations within density plots indicated a marginal effect of the DI (Online Resource $5)$. Indeed the number of seeds per pod was more influenced by the density of the whole plot (Fig. 3c) than by the immediate vicinity of individual gorse bushes represented by the DI. However, when the total number of seeds produced was used (Fig. 3d), we found no difference in the $R-V$ relationships among density plots.
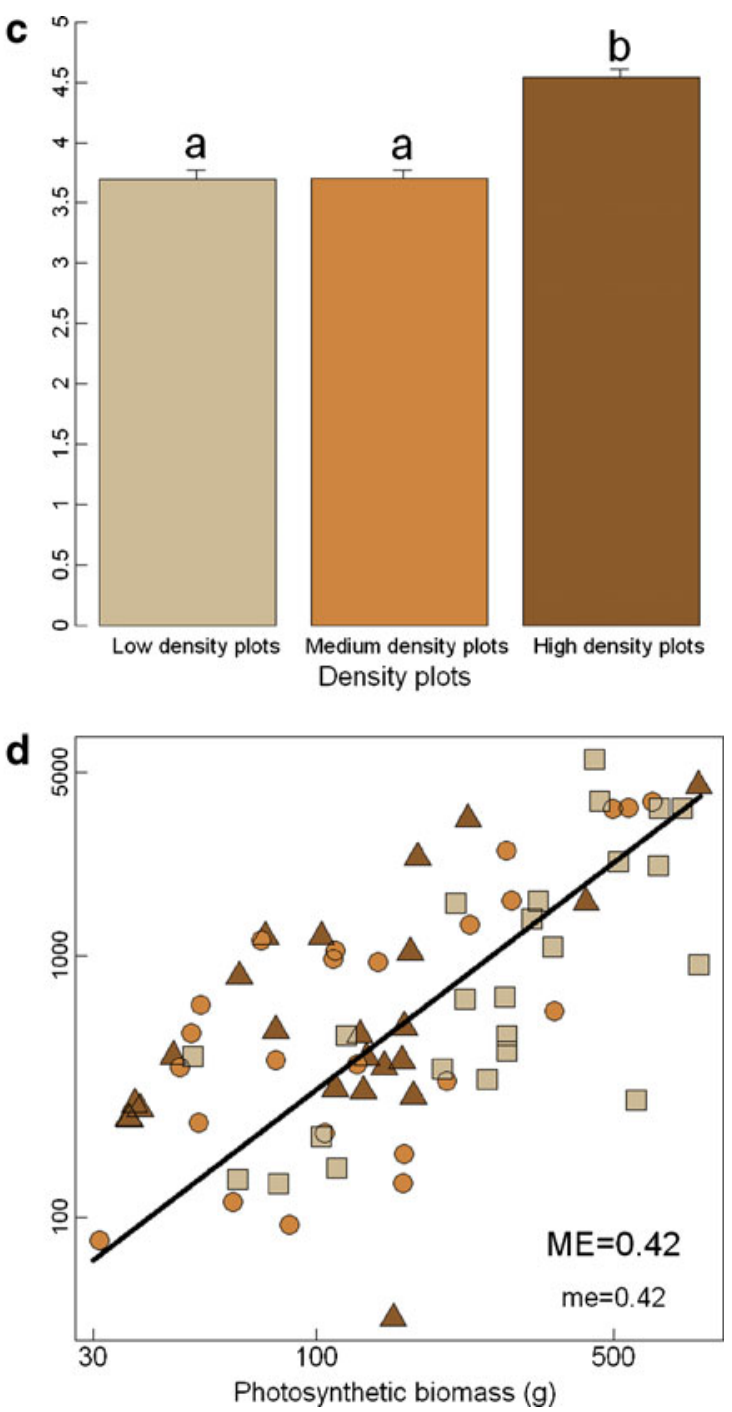

produce any seed. b Symbols, legend, meaning of the top left and the bottom-right graph labels and number of individuals per LI class are the same as in Fig 2b. c, d We classified the individuals per density plots and not per DI classes because the observed response is independent of the close neighbourhood (represented by the DI) within plots. d We show the overall relationship represented by the solid black line (no significant difference of slope between classes). The ME of the fitted relationship taking into account environmental variables (density plots) or not are shown as in Fig. 2. Light brown squares low density plots $(N=24)$, brown circle medium density plots $(N=24)$, dark brown triangle high density plots $(N=23(24-$ 1 operator mistake))

\section{Discussion}

4.1 On the use of $R-V$ relationships to study reproductive allocation of woody plants

Using BA (Eq. 1), it is tempting to conclude that reproductive allocation was strongly modified by light availability and reduced by the dry spring in 2011 (Fig. 2a, c). However, using PB (Eq. 2), the influence of environment variation on 
reproductive allocation was less obvious. Like in herbaceous plants, the main response to resource availability we identified was plasticity of growth (i.e. apparent plasticity), which in turn determined the reproductive output (Weiner et al. 2009a). Thus, future studies of size-dependent fecundity of woody plants should consider that $R-V$ relationships should be related to recent growth, and relationships using PB appeared appropriate according to our results.

We found a decreased in the $\mathrm{PB} /$ shoot ratio with plant size and in resource-poor environments (Online Resource 5 ). The proportion of support tissue increased correspondingly. This could have two opposite consequences: (1) an increase of the respiration cost to maintain support tissue which could reduce reproductive allocation (Online resource 1, Peters et al. 1988) and (2) an increase of the amount of carbohydrates and nutrients stored in the sapwood and inner bark (Hoch et al. 2003) that could be remobilized and represent an additional resource for reproduction. However, we found no significant effect on the $R-V$ relationships using $\mathrm{PB}$ neither of the $\mathrm{PB} /$ shoot ratio nor of any variable related to ontogeny. Therefore, the opposite consequences stated above may (1) have counterbalanced each other, (2) have only impacted the production of $\mathrm{PB}$, not directly the allocation to reproduction and (3) be stronger and detectable only for taller trees. Even though, changes due to ontogeny should be constantly taken into account in future studies of reproductive allocation of woody plants, and the $\mathrm{PB} /$ shoot ratio could be an indicator of these changes.

\subsection{Plasticity of reproductive allocation of the model species}

Analysis of the light gradient produced two results which suggested true plasticity in reproductive allocation: a modification in the $R-V$ slope for pod production in Eq. 2 (Fig. 2b), and a modification in the number of seeds per pod (Fig. 3a). However, alternative explanations need to be explored. First, uncontrolled effects that influence individuals sampled in different sites are likely to play a role. However no differences between plots were in conflict with our interpretation. For instance, when species composition of the understory varied (Online Resource 3), the encountered species were all typical of the same regional level of fertility (Augusto et al. 2010), and the decrease of reproductive allocation in shade did not concern these plots. Moreover, the effect of light was still significant after taking into account a random effect due to sampling in different locations (Online Resource 5, Fig. 2b). Second, a limitation in pollination in shade could be involved. However, pollinators of gorse are not influenced by the irradiance in forest stands (Herrera 1995). In addition the few species that bloom simultaneously with gorse are not abundant locally suggesting a low inter-specific competition for pollinators' service. Finally, Hornoy (2012) confirmed, in an experimental garden, that a decrease in light led to a decrease in flower initiation of gorse but did not change the fruit/flower ratio. Therefore, the most likely explanation of Figs. $2 b$ and $3 b$ is plasticity of reproductive allocation. However, some individuals remained tied to the main $R-V$ relationship. Genetic differences may explain this variability of plasticity (e.g. Clauss and Aarssen 1994).

When analysing the density sample, we observed an increase in the number of seeds per pod (Fig. 3c) in the densest plots. Plant-pollinator interactions may explain this result. When shrubs are isolated, one single pollinator may visit more flowers per plant thus leading to higher abortion of self-fecundated ovules to avoid genetic depression (Cibula and Zimmerman 1984). In dense areas, crosspollination is more likely and would increase the number of viable fecundated ovules per fruit, which would be consistent with our findings. In general, the response to increased intra-specific competition did not involve plasticity of reproductive allocation. The corresponding depletion of resource may be limited because (1) photosynthetic biomass is concentrated at the apex of the plant in dense thickets (i.e. in good light conditions) and (2) gorse is tolerant to poor nutrient availability (Drake 2011).

From our whole experimental design, we found evidence that our model species can display plasticity of reproductive allocation, limited to the response to light availability. To our knowledge, no previous studies have characterised the plasticity of this trait in woody plants.

\subsection{Plasticity of reproductive allocation and shade avoidance}

We observed that gorse bushes in shady sites showed modification associated with shade avoidance: thinner branches and longer internodes. The quantity of carbonbased constituents and biomass allocated to functions other than photosynthesis is reduced in cases of shade avoidance (Iason and Hester 1993; Poorter et al. 2012). Our results suggest a similar trade-off in the most limiting environments, making the production of photosynthetic tissues a priority, enabling the individual to survive and continue reproducing in the future. Moreover, green stems are the main component of PB of gorse. The structural and chemical modifications of the green stems associated with etiolation (Iason and Hester 1993) may results in the observed plasticity. While nutrient concentration may be reduced in the $\mathrm{PB}$, it is likely to be less variable in the reproductive organs to ensure the viability of the offspring. Therefore, a higher amount of PB may be needed to provide the necessary material and energy to build a single reproductive organ with fixed composition (Weiner et al. 2009b). 
4.4 Ecological significance of the plasticity of reproductive allocation

Like in herbaceous plants, plasticity was only observed by comparing the two extremes of the resource gradient (light in our study) (Weiner et al. 2009a). It is thus unlikely that plasticity is expressed in the case of small inter-annual variations in the environment. The successional niche hypothesis (Pacala and Rees 1998) is helpful to explore the ecological significance of our findings. Indeed the extreme variations in irradiance involved only occur during changes from the pioneer to late successional stages in forest or suddenly after a disturbance of the canopy. The successional niche hypothesis states that pioneer species (like gorse) should be excluded by over-competitors (trees in our case) but are maintained thanks to the short window of access to a high level of resource after a disturbance. This hypothesis is in agreement with the life cycle of gorse in our context. After a clear cut and the plantation of the next pine stand, when competition is low, the emergence of new individual gorse bushes is favoured. The new recruits mature and produce a large seed bank in full light conditions as we showed here. Because this seed bank can remain dormant for a long time, the species' ability to regenerate is stored in its seed bank (Beckage et al. 2005) until a new disturbance occurs. If plasticity of reproductive allocation is followed by improved survival in the forest succession, it could lead to a higher probability of maintaining a seed bank in the gap between two disturbances. However, to fit the $R-V$ relationships, we had to perform a single destructive harvest. Thus, we did not observe the fates of the plastic individuals. Answering the question of their future survival and of their reproductive output during the course of their lifetime is crucial to understand the ecological significance of plasticity of reproductive allocation.

\section{Conclusion}

We showed that the whole size of woody plants does not provide enough information to detect true plasticity of their reproductive allocation. Using a more appropriate variable, photosynthetic biomass, we demonstrated that the reproductive allocation of the studied species can indeed be plastic. Depending on their distribution along wide gradients of resource, other woody species may express this kind of plasticity. Pioneer species may be able to modify their reproductive allocation under different light regimes because they are known to develop mechanisms of shade avoidance, and plasticity of reproductive allocation may be part of this response. Particularly, species with green stems may show similar plasticity because shade avoidance response results in strong modification of their PB composition and may in turn modify the ability of PB to provide energy for reproduction. If plasticity of reproductive allocation confers higher survival in the shade, it could increase the ability of these pioneer species to maintain in forest systems with long unfavourable periods between two disturbances. Long-term studies are needed to better understand the ecological importance of plasticity of reproductive allocation of woody plants.

Acknowledgments We thank Mr. Jean Michel Beau from the French Forest National Office and Mr. Castagnet for giving us access to additional sampling sites. We are grateful to the INRA-UE570 Forêt Pierroton and UMR1202 BIOGECO teams, especially Laurent Severin, Luc Puzos and Celine Merdieu for their help in identification of sites and support in the field. We thank Alexandre Bosc for advice on measuring light and Alain Mollier, Christophe Nguyen, André Schneider and Frédérique Pellerin for discussion about statistical methods. We also thank David Achat, Mark Bakker, Jean Christophe Domec, Nathalie Gallegos, Céline Gire, Sylvie Millin, Sylvie Niollet, Loïc Prudhomme and Stéphane Thunot for technical help. We are also grateful for the suggestions made by the anonymous reviewers and editors.

\section{References}

Abe S, Motai H, Tanaka H, Shibata M, Kominami Y, Nakashizuka T (2008) Population maintenance of the short-lived shrub Sambucus in a deciduous forest. Ecology 89:1155-1167. doi:10.1890/062009.1

Atlan A, Barat M, Legionnet AS, Parize L, Tarayre M (2010) Genetic variation in flowering phenology and avoidance of seed predation in native populations of Ulex europaeus. J Evol Biol 23:362-371. doi:10.1111/j.1420-9101.2009.01908.x

Augusto L, Bakker MR, Morel C, Meredieu C, Trichet P, Badeau V, Arrouays D, Plassard C, Achat D, Galley-Budynek A (2010) Is 'grey literature' a reliable source of data to characterize soils at the scale of a region? - a case study in a maritime Pine forest in south-western France. Eur J Soil Sci 61:807-822. doi:10.1111/ j.1365-2389.2010.01286.x

Barat M, Tarayre M, Atlan A (2007) Plant phenology and seed predation: interactions between gorses and weevils in Brittany (France). Entomol Exp Appl 124:167-176. doi:10.1111/j.15707458.2007.00565.x

Beckage B, Lavine M, Clark JS (2005) Survival of tree seedlings across space and time: estimates from long-term count data. $\mathrm{J}$ Ecol 93:1177-1184. doi:10.1111/j.1365-2745.2005.01053.x

Bowman G, Tarayre M, Atlan A (2008) How is the invasive gorse Ulex europaeus pollinated during winter? A lesson from its native range. Plant Ecol 197:197-206. doi:10.1007/s11258-007-9370-1

Cibula DA, Zimmerman M (1984) The effect of plant density on departure decisions. Testing the marginal value theorem using bumblebees and Delphinium nelsonii. Oikos 43:154-158. doi: $10.2307 / 3544763$

Clauss MJ, Aarssen LW (1994) Phenotypic plasticity of size-fecundity relationships in Arabidopsis thaliana. J Ecol 82:447-455. doi: $10.2307 / 2261254$

Debain S, Curt T, Lepart J, Prevosto B (2003) Reproductive variability in Pinus sylvestris in southern France: implications for invasion. $\mathrm{J}$ Veg Sci 14:509-516. doi:10.1111/j.1654-1103.2003.tb02177.x

Dodd ME, Silvertown J (2000) Size-specific fecundity and the influence of lifetime size variation upon effective population size in Abies balsamea. Heredity 85:604-609. doi:10.1046/j.13652540.2000.00822.x 
Drake DC (2011) Invasive legumes fix N-2 at high rates in riparian areas of an N-saturated, agricultural catchment. J Ecol 99:515523. doi:10.1111/j.1365-2745.2010.01787.x

Gendron F, Messier C, Comeau PG (1998) Comparison of various methods for estimating the mean growing season percent photosynthetic photon flux density in forests. Agric For Meteorol 92:55-70. doi:10.1016/S0168-1923(98)00082-3

Hegyi F (1974) A simulation model for managing jack-pine stands. In: Fries J (ed) Growth model for tree and stands simulation, vol Research, Note 30. Royal College of Forestry, Stockholm, pp 74 90

Herrera CM (1995) Microclimate and individual variation in pollinators: flowering plants are more than their flowers. Ecology 76:1516-1524. doi:10.2307/1938153

Hoch G, Richter A, Korner C (2003) Non-structural carbon compounds in temperate forest trees. Plant Cell Environ 26:10671081. doi:10.1046/j.0016-8025.2003.01032.x

Hornoy B (2012) Evolutionary processes contributing to the invasive success of common gorse, Ulex europaeus [in French]. PhD, University of Rennes 1, Rennes

Iason GR, Hester AJ (1993) The response of heather (Calluna vulgaris) to shade and nutrients - predictions of the carbon-nutrient balance hypothesis. J Ecol 81:75-80. doi:10.2307/2261225

Jennings S, Baima AMV (2005) The influence of population and forest structure on fruit production in mahogany (Swietenia macrophylla King) and their consequences for sustainable management. Int For Rev 7:363-369. doi:10.1505/ifor.2005.7.4.363

Klinkhamer PGL, Meelis E, Dejong TJ, Weiner J (1992) On the analysis of size-dependent reproductive output in plants. Funct Ecol 6:308-316. doi:10.2307/2389522

Lee WG, Allen RB, Johnson PN (1986) Succession and dynamics of gorse (Ulex europaeus L) communities in the Dunedin Ecological District South-Island, New-Zealand. N Z J Bot 24:279-292

Louveaux J, Albisetti M, Delangue M, Theurkau M (1966) Les modalités de l'adaptation des abeilles (Apis mellifica L.) au milieu naturel. Annales de l'Abeille 9:323-350

McConnaughay KDM, Coleman JS (1999) Biomass allocation in plants: ontogeny or optimality? A test along three resource gradients. Ecology 80:2581-2593. doi:10.2307/177242
Newton PF, Jolliffe PA (1998) Assessing processes of intraspecific competition within spatially heterogeneous black spruce stands. Can J For Res 28:259-275. doi:10.1139/cjfr-28-2-259

Niklas KJ, Enquist BJ (2003) An allometric model for seed plant reproduction. Evol Ecol Res 5:79-88

Obeso JR (2002) The costs of reproduction in plants. New Phytol 155:321-348. doi:10.1046/j.1469-8137.2002.00477.x

Pacala SW, Rees M (1998) Models suggesting field experiments to test two hypotheses explaining successional diversity. Am Nat 152:729-737. doi: $10.1086 / 286203$

Peters RH, Cloutier S, Dube D, Evans A, Hastings P, Kaiser H, Kohn D, Sarwerfoner B (1988) The allometry of the weight of fruit on trees and shrubs in Barbados. Oecologia 74:612-616. doi:10.1007/bf00380061

Poorter H, Niklas KJ, Reich PB, Oleksyn J, Poot P, Mommer L (2012) Biomass allocation to leaves, stems and roots: meta-analyses of interspecific variation and environmental control. New Phytol 193:30-50. doi:10.1111/j.1469-8137.2011.03952.x

Porte A, Bosc A, Champion I, Loustau D (2000) Estimating the foliage area of Maritime pine (Pinus pinaster Ait.) branches and crowns with application to modelling the foliage area distribution in the crown. Ann For Sci 57:73-86

Puentes A, Basanta M (2002) Architecture of Ulex europaeus: changes in the vertical distribution of organs in relation to plant height and season. J Veg Sci 13:793-802. doi:10.1111/j.1654-1103.2002.tb02109.x

R Development Core Team (2010) R: A Language and Environment for Statistical Computing. Vienna, Austria: R Foundation for Statistical Computing. ISBN 3-0051-07-0, URL http://www.Rproject.org/.

Weiner J (2004) Allocation, plasticity and allometry in plants. Perspect Plant Ecol Evol Syst 6:207-215. doi:10.1078/1433-8319-00083

Weiner J, Campbell LG, Pino J, Echarte L (2009a) The allometry of reproduction within plant populations. J Ecol 97:1220-1233. doi:10.1111/j.1365-2745.2009.01559.x

Weiner J, Rosenmeier L, Massoni ES, Vera JN, Plaza EH, Sebastia MT (2009b) Is reproductive allocation in Senecio vulgaris plastic? Botany-Botanique 87:475-481. doi:10.1139/b09-012

Zuur AF, Leno EN, Walker NJ, Saveliev AA, Smith GM (2009) Mixed effects models and extensions in ecology with R, Statistics for Biology and Health. Springer, New York 